\title{
LC-MS AND ESI-MS QTOF-MS ANALYSIS OF GLYCEROPHOSPHOLIPID AND TRIACYLGLYCEROL SPECIES IN DEVELOPING WILD ARTICHOKE ACHENES
}

\author{
Moufida A. OUESLATI, ${ }^{\mathrm{a}}$ Justin RENAUD, ${ }^{\mathrm{b}}$ Ghayth RIGANE, ${ }^{\mathrm{cd}, *}$ Aynur GUNENC, ${ }^{\mathrm{e}}$ \\ Ridha Ben SALEM, ${ }^{\mathrm{c}}$ Sadok BOUKHCHINA, ${ }^{\mathrm{e}}$ Farah HUSSAINIAN ${ }^{\mathrm{f}}$ and Paul M. MAYER ${ }^{\mathrm{b}}$ \\ ${ }^{a}$ College of Applied Medical Sciences in al Jubail, Deanship of preparatory year and supporting studies and the department \\ of Respiratory Care, Imam Abdulrahman Bin Faisal University, PO. Box 1982, Dammam 31441, Saudi Arabia \\ ${ }^{\mathrm{b}}$ Laboratory of Mass Spectrometry, Department of Chemistry, University of Ottawa, Ottawa ON Canada \\ ${ }^{c}$ Laboratory of Organic Chemistry LR17ES08, Sciences Faculty of Sfax, B.P 1171, 3038 Sfax, University of Sfax, Tunisia \\ ${ }^{\mathrm{d}}$ Chemistry-Physics Department, Sciences and Technology Faculty, B. P 380, 9100, Sidi Bouzid, University of Kairouan, Tunisia \\ ${ }^{\mathrm{e}}$ Laboratory of Food Science and Nutrition, Department of chemistry, University of Carleton, Ottawa,,Ontario, Canada \\ ${ }^{\mathrm{f}}$ Laboratory of Lipids Biochemistry, Department of Biology, University of Sciences of Tunis, 2092 El Manar II, Tunisia
}

The present study, aimed at presenting comprehensive data on the content of storage and structure lipids of the unexploited wild Onopordum acanthium vegetable oil during achenes development. By using ESI-MS, and Total mass spectral intensities, we identified and determined the proportions of sixteen TAG species. POP, SOP, OLS, GLL, ALO and PLLn were detected for the first time. In addition five phospholipid (PL) classes were discerned. Interestingly, each stage of maturation was characterized by the dominance of one or two phospholipid classes with generally Phosphatidylglycerol as the prominent form in all collection dates $(48.2 \%$ of total PLs). Various PL molecular species were detected in each class of glycerophospholipid. The main acyl chains were found to be palmitic; linoleic and linolenic acids.

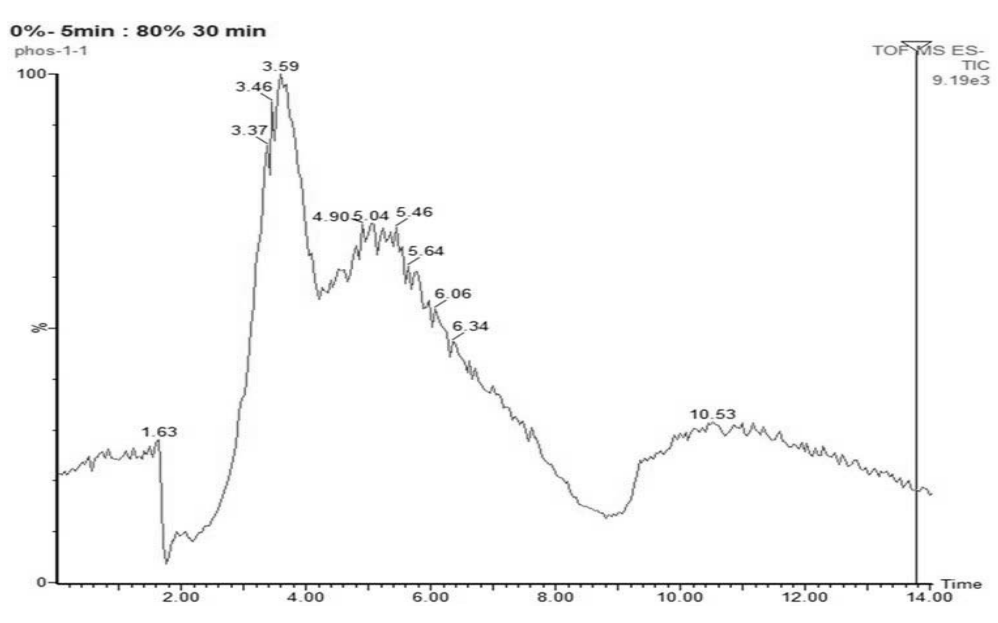
Unexpectedly, linolenic acid was found more frequently in phospholipids than in triglycerides. Our findings provide useful information about a new source of vegetable oil that can be exploited in food or non-food applications.

\section{INTRODUCTION}

The Onopordum acanthium L. also named wild artichoke belongs to the tribe Cardueae (Asteraceae family) ${ }^{1}$ and is widely distributed over the world. It is native to Northern Africa, Europe, the Canary Islands, the Caucasus, Southwest and Central Asia, and Iraq. It grows at open, sandy or stony habitats. ${ }^{2}$ The plant is characterized by a significant fruit and biomass productivity. Consequently, the species is gaining interest as a potential novel commercial crop for multiple uses (i.e. medicinal plant, bioenergy, and vegetable oil production). Metabolites isolated from the species of the genus Onopordum include sesquiterpenoids, flavonoids, acetylenic compounds, steroids, 
triterpenes, lipids and nitrogen containing compounds. However, data documenting the oil content of wild artichoke are sparse $\mathrm{e}^{3,4}$ and major or minor lipid accumulation during seed maturation have never been conducted before our first report in fatty acids and phytosterols distribution. ${ }^{5}$ In order to continue our investigation of the lipid composition of the present oil we studied the evolution of TAG species and phospholipid classes in the wild artichoke during achenes maturation. This investigation will offer a useful tool for the future improvement of yield, quality or composition of the oil produced from the achenes for diverse industrial use (fuel, food, cosmetic, pharmaceutical). TAGs are an important dietary source of energy and nutrition for humans and their compositional analysis merits extensive interest. In addition, TAG profiles are used in the food industry as a good fingerprint for detecting adulteration. ${ }^{6}$ Several works ${ }^{7}$ have reported that glycerophospholipids, which are essential components of cell membranes, are endowed with beneficial effects on human health and have a wide array of food and non-food applications, mainly as nontoxic biodegradable emulsifiers, industrial lubricants, and nutritional supplements. The study of these oil components to determine the oleate/linoleate ratio accumulated into the seeds is a valuable criteria that determine the physicochemical properties and the quality of the oil. ${ }^{8}$ Traditionally, analysis of TAGs and phospholipid classes was accomplished by TLC, and gas chromatography. A drawback of GC-MS often involves the liberation of fatty acids from more complex lipid species, losing all information regarding its initial state. Soft ionization techniques coupled with modern mass spectrometers have proven valuable in characterizing components of complex lipids. Electrospray ionization mass spectrometry (ESI-MS) offers the possibility of directly analyzing the total lipid extract and the detection of large numbers of individual lipid ions, in a single experiment and in complex mixtures. ${ }^{9}$ Several studies have demonstrated the utility of LC-MS in qualitative and quantitative analyses of phospholipid components. ${ }^{10}$ The purpose of this study was to analyze seed oils, obtained from $O$. acanthium achenes during their maturation, by ESI-QTOF-MS and LC-MS-MS in an attempt to determine the distribution of various molecular species of triacylglycerols and glycerophospholipids and for the first time, the TAG and PL components in the wild artichoke oil. Such information is valuable for many aspects of vegetable oil production, including the assessment of oil quality and product development.

\section{MATERIALS AND METHODS}

\section{Samples}

Fruits of O.acanthium $L$ were collected in 2010 from plants growing wild in El Kef region of Tunisia $\left(8^{\circ} 07^{\prime}(\mathrm{E}), 36^{\circ} 1^{\prime}(\mathrm{N}), 780 \mathrm{~m}\right.$ (altitude)) at different stages of their maturity measured at 5,14 , 26,38 , and 45 days after flowering (DAF). ${ }^{5}$ The El Kef region is located in the North-West of Tunisia and is characterized by a low annual rainfall of $700 \mathrm{~mm}$ and mean annual temperature of $15.8^{\circ} \mathrm{C}$. The voucher specimens were deposited in the laboratory herbarium of the University of Sciences of Tunis. Following plant harvest, $70 \mathrm{~g}$ of seeds husked, cleaned, dried $\left(70^{\circ} \mathrm{C}\right)$ and ground. The oil was extracted using petroleum ether for $6 \mathrm{~h}$. The solvent was evaporated using a rotary evaporator at $50^{\circ} \mathrm{C}$ and was dried by using a gentle stream of nitrogen and stored at $-20{ }^{\circ} \mathrm{C}$ prior to analysis.

\section{Reagent and standards}

Methanol, acetone and n-hexane were LC grade and were purchased from Fisher Scientific Company (Ottawa, Canada). Chloroform, acetic acid and isopropanol were purchased from Panreac Quimica SA. (Barcelona, Spain). Petroleum ether and lithium hydroxide was supplied by Sigma Aldrich (St. Louis, USA). Glyceryl-tripalmitin standard (PPP, $\geq 99 \%$ ) was acquired from Sigma-Aldrich (St Louis, USA).

\section{Analysis of phospholipids with LC-MS- QTOF-MS}

Liquid chromatography was performed on a HP $1050 \mathrm{Ti}$ series gradient pump having a $10 \mu \mathrm{L}$ sample loop. A Lichrospher 100 diol column $(250 \mathrm{~mm} \times 4.6 \mathrm{~mm}, 5 \mu \mathrm{m}$ particle size; Merck, Germany) was used to separate phospholipids by class. The binary solvent gradient consisted of solvent mixture A: hexane-isopropanol-acetic acid-triethylamine $(82: 17: 1: 0.08 \quad \mathrm{v} / \mathrm{v} / \mathrm{v} / \mathrm{v})$ and mixture B: isopropanol-water-acetic acid-triethylamine $(85: 14: 1: 0.08 \mathrm{v} / \mathrm{v} / \mathrm{v} / \mathrm{v})$. The gradient started at $5 \%$ mixture $\mathrm{B}$ then increased to $80 \%$ over $30 \mathrm{~min}$. This composition was maintained for $1 \mathrm{~min}$ before being returned to $5 \% \mathrm{~B}$ over $7 \mathrm{~min}$ and maintained another $2 \mathrm{~min}$. The flow rate of $1 \mathrm{ml} / \mathrm{min}$ through the columns was subsequently split to $100 \mu \mathrm{L} / \mathrm{min}$ using a micro-splitter valve (Upchurch Scientific, Oak Harbor, Wash, Manchester, UK) before introduction to the 
electrospray ionization source. Glycerophospholipids were detected with a Quattro-LC (Waters Micromass, Manchester, UK) electrosprayionization triple-quadrupole mass spectrometer (operating in negative ion mode) employing the MassLynx (v.4.0) control and processing software. The $100 \mu \mathrm{l} / \mathrm{min}$ flow of eluent was passed through the electrospray capillary at $-3.8 \mathrm{kV}$. The source block temperature was $80^{\circ} \mathrm{C}$ and the cone voltage was set at $-70 \mathrm{~V}$. $\mathrm{N}_{2}$ drying gas was passed coaxially to the capillary with a flow rate of approximately $100 \mathrm{~L} / \mathrm{h}$.

\section{Triacylglycerols analysis (ESI-MS-QTOF-MS)}

TAGs were monitored by direct injections using the same QTOF electrospray ionization quadrupole time of flight mass spectrometer (operating in a positive ion mode). TAGs were identified as lithium $\left(\mathrm{Li}, \mathrm{m} / \mathrm{z}\right.$ 7) adducts $[\mathrm{M}+\mathrm{Li}]^{+}$. Infusion of TAGs in solutions containing lithium $(2 \mathrm{mM})$ yields abundant $[\mathrm{M}+\mathrm{Li}]+$ ions on ESI-MS, and provides improved spectra for characterization. The TAG containing solution $(20 \mu \mathrm{l})$ was dissolved in a mixture of tetrahydrofurane-methanol- $\quad \mathrm{LiCl} \quad(82: 17: 1.025$, $\mathrm{v} / \mathrm{v} / \mathrm{v} /$ ) and injected into a $20 \mu 1$ sample loop where it was carried with methanol at a flow of $75 \mu 1 / \mathrm{min}$ to the electrospray capillary that was held at $+3.3 \mathrm{kv}$. A collision energy was chosen to obtain reliable signal intensity and the collision gas (argon) pressure was set to $4 \times 10^{-4} \mathrm{mbar}$. The source temperature was $100{ }^{\circ} \mathrm{C}$ and the cone voltage was set at $50 \mathrm{~V}$. Nitrogen with flow rate of approximately $440 \mathrm{~L} \mathrm{~h}^{-1}$ was used as the drying gas and $\mathrm{N}_{2}$ cone passed around the mass spectrometer entrance at a rate of $250 \mathrm{~L} \mathrm{~h}^{-1}$.ESI-MS was focused on mass ranges of $700-1100 \mathrm{~m} / \mathrm{z}$ and the proportion of individual TAG species was estimated by molecular ion intensity, following isotope correction procedure as reported by Tlili et al. ${ }^{11}$ Total amounts of individual TAGs were estimated by comparison with the total ion count of the internal standard (glyceryl-tripalmitate, $300 \mu \mathrm{g} \mathrm{ml}^{-1}$ ).

\section{Statistical analysis}

The differences between the means and medians composition of triacylglycerols and phospholipids and their components were measured using the Student-Newman-Keuls tests. All the statistical analysis was performed with the STATA (v.9.0) software. Tests were deemed to be significant when $\mathrm{p}$-value $<0$. 05. Descriptive analyses, one-way ANOVA, (XLSTAT trial version, 2016) was also used.

\section{RESULTS AND DISCUSSION}

\section{Oil accumulation}

The $O$. acanthium seeds accumulate carbon and energy in the form of TAG in order to feed the embryo during germination. As we have previously reported $^{5}$ seed development, in the wild artichoke, is roughly divided into five stages that started 5 days after flowering (DAF) and extending to 45 DAF. The mean content of total lipids (Table 1) varied significantly from $\sim 16 \mathrm{~g} / \mathrm{Kg}$ of dry weight (DW) in the first stage of seed maturation (5 DAF) to $\sim 153 \mathrm{~g} / \mathrm{kg}$ DW in the fully mature seeds (45 DAF). Such information which were determined for the first time are useful in term of determining the time of harvest to obtain optimal oil fruit composition. $^{5}$

\section{Changes in total TAG content}

TAGs from plant oils are an important part of the human diet and knowledge of the oil composition is relevant from a nutritional point of view. ${ }^{8}$ Fig. 1 shows the TAG evolution over seeds development. We determined that the total TAG concentration $(\mathrm{mg} / 100 \mathrm{mg}$ of oil) in the wild artichoke achenes most influenced by their development state. The accumulation of total TAGs into achenes started early. Immature seeds (5 DAF and $14 \mathrm{DAF}$ ) have accumulated more than $70 \%$ of total storages lipids and 26 DAF was the optimum period of their biosynthesis. At this date, the TAG concentration reached a maximum of $97 \%$ of total lipids. These result differ from that found in other edible oils such as corn oil and flaxseed oil for which total TAGs did not exceed $30 \mathrm{mg} / 100 \mathrm{mg}$ of oil in immature fruits. ${ }^{12,13}$ This observation might be the consequence of the protein and sugar catabolism, and cytosolic glycolysis. Craig et al. ${ }^{13}$ have shown that import and cleavage of dissacharides play a key role in triggering the seed maturation process and determining the strength of sink tissues. On the other hand the former phase was followed by significant decrease $(p<0.001)$ in total TAG content, then a significant increase in mature seeds. Taking into account that the wild artichoke cypsela are known to possess a fast germination and also high dormancy and longevity, it is reasonable to 
expect that important levels of TAGs in fully mature fruits which are a reflection of the greater need of these seeds for carbon and energy resources mostly in the form of TAGs. It is noteworthy that the significant decrease in total TAG content observed at 38DAF could be due to a higher synthesis of phospholipids since these two glycerolipids are derived from the same precursor (phosphatidate).

\section{Changes TAGs molecular species during cypsela development}

Fig. 2 shows a typical TAG ESI-MS profile. Total mass spectral intensities were used to estimate the proportions of different TAG species. The identified TAGs are described in Table 1. Their nomenclature are generally initiated by the initial of the FA trivial names and arranged according to their $s n-1,2$ and 3 positions. The inner $(s n-2)$ and outer $(s n l, 3)$ fatty acids can be determined by the relative intensity of the product ions, ${ }^{14,15}$ however no distinction is made between the absolute identity of the $s n-1$ and $s n-3$ fatty acids. Based on previous study, ${ }^{16}$ the $s n-2$ position was attributed to most unsaturated fatty acid (for example, a TAG containing two oleic and one linoleic acid group is noted as OLO). Quantitatively, we have identified sixteen triacylglycerols in the wild artichoke oil during the fruits maturation. The major forms (Fig. 2) were LLL (19-27 mg/100mg of oil) > LLO (14-19 mg/100mg of oil) > PLL (10-13 $\mathrm{mg} / 100 \mathrm{mg}$ of oil $)>$ OLO $(6-12 \mathrm{mg} / 100 \mathrm{mg}$ of oil $)>$ PLO (5-7 mg/100mg of oil) $>$ OOS (4-9 mg/100mg of oil). These TAG species, together accounted for up to $75 \%$ of total TAG molecular species. The nearest five TAG species based on abundance (PLP, PLO,POO, OOO and OOE) were all present in lower amounts, that is, the proportion of each one was less than $7 \%$ of the total TAG concentration. Some monounsaturated species (POP and SOP), diunsaturated and tri-unsaturated species such as OLS, GLL, ALO and PLL ${ }_{n}$, were determined for the first time in the wild artichoke oil. Among the major species, LLL exhibited the most significant increase during the five episodes of growth (from $\sim 19$ to $\sim 27 \mathrm{mg} / 100 \mathrm{mg}$ oil) whereas no significant difference $(p>0.05)$ was observed for LLO and OLO species. This could reflect the highly efficient desaturation of oleic to linoleic acid ( $\Delta 12$-desaturase) and indicated that the desaturation step was favoured by the accumulation of the substrate. Moreover, the presence of high levels of TAG species that mostly incorporated palmitic, oleic and linoleic acid (Table 1) rather than other fatty acids could reflect the selectivity of the specific acyltransferase enzymes of the Kennedy pathway (G3PAT, LPAAT, PAP et DAGAT) towards the former fatty acids. Salas et al. ${ }^{17}$ reported that the specificity of the aforementioned acyltransferases broadly determine the fatty acid composition of the accumulating glycerolipid species. For instance, G3PAT, shows a preference for palmitoyl-CoA whereas, LPAAT has, a strong selectivity for oleoyl-CoA in most plants. In our case we suggest that linoleoyl-CoA could also be an effective substrate for $O$. acanthium G3PAT since a high flux of linoleic acid into the extraplastidial acylCoA pool in $O$. acanthium achenes was recorded. Contrary to the former works, ${ }^{18,19}$ we did not detect any hydroxyl, nor epoxy TAG species. This could be due to the geographical growth zone, the soil density and the climatic conditions (light and temperature) that affect the biosynthesis of unusual FA and their assembly into TAGs. In comparison to other edible oils, in particular Corn oil and cotton oils that yield less than $20 \%$ of oil, and contain the trilinoleine as the major TAG species, we can consider the wild artichoke seeds a promising source of edible lipids.

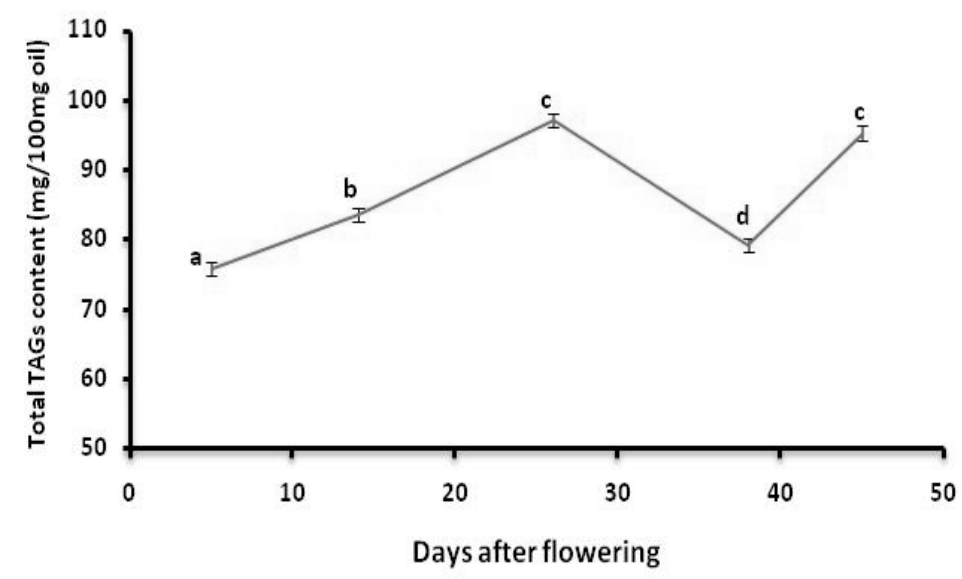

Fig. 1 - Accumulation of total triacylglycerols during achenes maturation. 


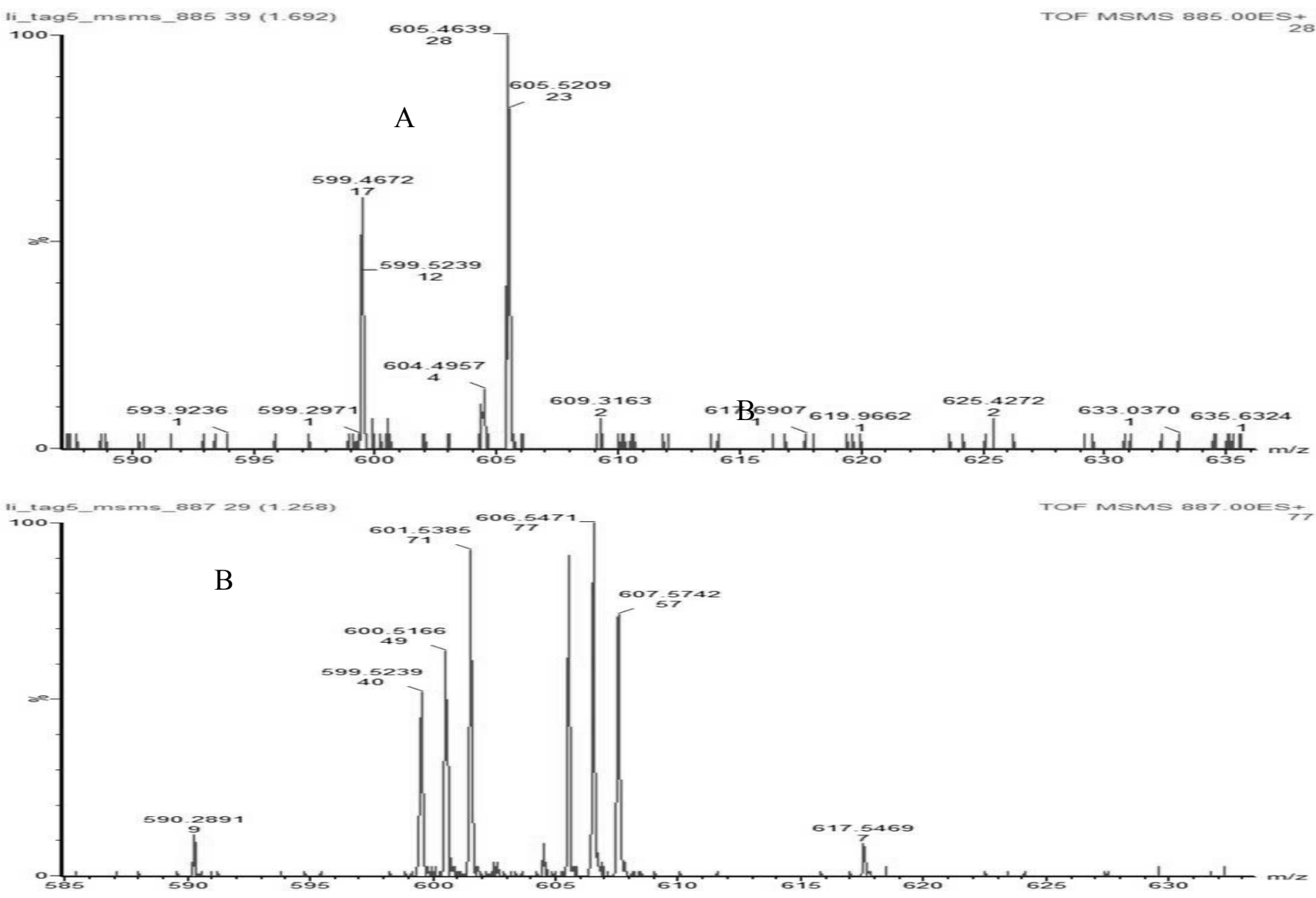

Fig. 2 - MS-MS spectra of the trilinolein (LLL, m/z 885) (A) and dilinoleo-olein (LLO, m/z 897) (B) as lithium adducts $[\mathrm{M}-\mathrm{H}+\mathrm{Li}]^{+}$.

Table 1

Triacylglycerol profile (mg/100 $\mathrm{mg}$ of oil) of the wild artichoke seed oil

\begin{tabular}{|c|c|c|c|c|c|c|}
\hline $\begin{array}{l}\text { TAG } \\
\text { (mg/100mg oil) }\end{array}$ & {$[\mathbf{M}-\mathbf{H}+\mathbf{L i}]+$} & 5DAF & 14 DAF & 26 DAF & 38 DAF & 45 DAF \\
\hline PLP & 837 & $1.755 \pm 0.063^{\mathrm{a}}$ & $2.335 \pm 0.12^{\mathrm{a}}$ & $2.11 \pm 0.43^{\mathrm{a}}$ & $0.895 \pm 0.1^{\mathrm{b}}$ & $1.66 \pm 0.23^{\mathrm{a}}$ \\
\hline POP & 839 & $0.395 \pm 0.03^{\mathrm{d}}$ & $0.884 \pm 0.036^{\mathrm{g}}$ & $0.355 \pm 0.063^{\mathrm{d}}$ & $0.635 \pm 0.035^{\mathrm{f}}$ & $0.5 \pm 0.028^{\mathrm{d}}$ \\
\hline PLnL & 859 & $1.375 \pm 0.07^{\mathrm{c}}$ & ND & $0.75 \pm 0.00^{\mathrm{e}}$ & ND & $0.41 \pm 0.019^{\mathrm{h}}$ \\
\hline PLL & 861 & $10.79 \pm 0.438^{\mathrm{i}}$ & $12.75 \pm 0.49^{j}$ & $11.64 \pm 0.1^{1 \mathrm{k}}$ & $8.67 \pm 0.07^{1}$ & $10.4 \pm 0.3^{\mathrm{i}}$ \\
\hline PLO & 863 & $7.39 \pm 0.15^{\mathrm{m}}$ & $3.77 \pm 0.38^{\mathrm{n}}$ & $6.16 \pm 0.93^{p}$ & $5.57 \pm 0.1^{\mathrm{p}}$ & $5.22 \pm 0.128^{\mathrm{p}}$ \\
\hline POO & 865 & $1.82 \pm 0.014^{\mathrm{a}}$ & $2.9 \pm 0.056^{\mathrm{b}}$ & $3.71 \pm 0.169^{c}$ & $2.48 \pm 0.5^{\mathrm{d}}$ & $4.49 \pm 0.48^{\mathrm{c}}$ \\
\hline SOP & 867 & $0.39 \pm 0.042^{\mathrm{b}}$ & $0.485 \pm 0.035^{\mathrm{b}}$ & $1.35 \pm 0.22^{\mathrm{a}}$ & $0.68 \pm 0.11^{\mathrm{b}}$ & $0.34 \pm 0.042^{\mathrm{b}}$ \\
\hline LLL & 885 & $18.92 \pm 0.127^{\mathrm{c}}$ & $21.83 \pm 0.25^{\mathrm{e}}$ & $26.59 \pm 0.586^{\mathrm{b}}$ & $21.52 \pm 0.68^{\mathrm{e}}$ & $26.07 \pm 0.084^{b}$ \\
\hline LLO & 887 & $14.195 \pm 0.05^{\mathrm{a}}$ & $14.2 \pm 0.13^{\mathrm{a}}$ & $19.025 \pm 0.38^{\mathrm{b}}$ & $14.56 \pm 0.37^{\mathrm{a}}$ & $14.38 \pm 0.113^{\mathrm{a}}$ \\
\hline OLO & 889 & $6.265 \pm 0.22^{\mathrm{a}}$ & $8.3 \pm 0.17^{\mathrm{b}}$ & $10.215 \pm 0.29^{c}$ & $7.47 \pm 0.08^{\mathrm{b}}$ & $11,75 \pm 0.912^{\mathrm{d}}$ \\
\hline 000 & 891 & $2.41 \pm 0.13^{\mathrm{a}}$ & $4.065 \pm 0.36^{\mathrm{b}}$ & $5.405 \pm 0.12^{\mathrm{c}}$ & $3.18 \pm 0.19^{\mathrm{d}}$ & $4.54 \pm 0.31^{\mathrm{b}}$ \\
\hline OOS & 893 & $4.47 \pm 0.6 \mathrm{a}$ & $7.68 \pm 0.3^{b}$ & $3.97 \pm 0.1^{\mathrm{a}}$ & $9.02 \pm 0.017^{\mathrm{c}}$ & $6 \pm 0.14^{\mathrm{d}}$ \\
\hline OLS & 915 & $0.795 \pm 0.007^{\mathrm{a}}$ & $0.635 \pm 0.09^{\mathrm{e}}$ & $0.815 \pm 0.035^{\mathrm{a}}$ & $0.94 \pm 0.38^{\mathrm{a}}$ & $0.47 \pm 0.0424^{\mathrm{f}}$ \\
\hline GLL & 917 & $2.2 \pm 0.014^{\mathrm{a}}$ & $2.2 \pm 0.014^{\mathrm{a}}$ & $2.26 \pm 0.098^{\mathrm{a}}$ & $1.46 \pm 0.11^{\mathrm{a}}$ & $6.06 \pm 0.784^{\mathrm{b}}$ \\
\hline ALO & 919 & $1.19 \pm 0.028^{\mathrm{a}}$ & $1.16 \pm 0.07^{\mathrm{a}}$ & $1.22 \pm 0.014^{\mathrm{a}}$ & $0.81 \pm 0.053^{\mathrm{b}}$ & $0.45 \pm 0.028^{\mathrm{c}}$ \\
\hline OOE & 921 & $1.99 \pm 0.12^{\mathrm{a}}$ & $1.1 \pm 0.028^{\mathrm{b}}$ & $2.042 \pm 0.053^{\mathrm{a}}$ & $1.16 \pm 0.044^{b}$ & $3.92 \pm 0.11^{\mathrm{d}}$ \\
\hline $\begin{array}{l}\text { Oil yield } \\
(\mathrm{g} / \mathrm{Kg} \mathrm{DW})\end{array}$ & & $16.03 \pm 1.5$ & $9.1 \pm 1.83$ & $101.32 \pm 7.21$ & $120.86 \pm 8.6$ & $152.66 \pm 3.46$ \\
\hline
\end{tabular}

Mean values with different letters within a row are significantly different, at $\mathrm{p}<0.05$; A, arachidic acid; E: erucic acid; G: gadoleic acid; L, linoleic acid; Ln, linolenic acid; O, oleic acid; P, palmitic acid; S, stearic acid; DAF: Days After Flowering. Each value is a mean \pm standard deviation (SD) of a triplicate analysis performed on different samples. 
Table 2

Accumulation of Phospholipid classes (\% of total phospholipids) during seeds maturation

\begin{tabular}{llllll}
\hline \multicolumn{1}{c}{ Ripening stage } & \multicolumn{5}{c}{ Phospholipid classes } \\
\hline & PA & PE & PG & PC & PI \\
5 DAF & $51.9 \pm 0.1^{\mathrm{a}}$ & $6.8 \pm 0.54^{\mathrm{e}}$ & $36 \pm 0.01^{\mathrm{f}}$ & $1.01 \pm 0.12^{\mathrm{g}}$ & $3.04 \pm 0.06^{\mathrm{h}}$ \\
$14 \mathrm{DAF}$ & $21.2 \pm 1.53^{\mathrm{b}}$ & $12 \pm 1^{\mathrm{i}}$ & $62.2 \pm 0.7^{\mathrm{d}}$ & $1 \pm 0.0^{\mathrm{g}}$ & $3.96 \pm 0.05^{\mathrm{h}}$ \\
$26 \mathrm{DAF}$ & $13.9 \pm 0,15^{\mathrm{c}}$ & $4.97 \pm 0.16^{\mathrm{k}}$ & $36 \pm 1^{\mathrm{f}}$ & $2 \pm 0.01^{1}$ & $43 \pm 1^{\mathrm{d}}$ \\
$38 \mathrm{DAF}$ & $11.92 \pm 0.13^{\mathrm{d}}$ & $10 \pm 0.01^{\mathrm{d}}$ & $69.9 \pm 0.13^{\mathrm{c}}$ & $2 \pm 0.0^{\mathrm{l}}$ & $6 \pm 0.05^{\mathrm{a}}$ \\
$45 \mathrm{DAF}$ & $21 \pm 0.02^{\mathrm{b}}$ & $21.7 \pm 0.05^{\mathrm{b}}$ & $29.7 \pm 0.52^{\mathrm{d}}$ & $1 \pm 0.0^{\mathrm{g}}$ & $26.15 \pm 0.91^{\mathrm{c}}$ \\
\hline
\end{tabular}

Mean values with different numbers within a column and a row are significantly different, at $\mathrm{p} \leq 0.05$; DAF: Days after flowering. PA: Phosphatidic acid, PE: phosphatidylethanolamine, PG phosphatidylglycerol, PC: phosphatidylcholine,PI: phosphatidylinositol

\section{Glycerophospholipid distribution}

Identification of the phospholipid species and their temporal occurrence provides a possible way to produce seed oil with high additional value. ${ }^{20}$ Five major glycerophospholipid classes were determined as phosphatidic acid (PA), phosphatidylethanolamine (PE), phosphatidylglycerol (PG), phosphatidylcholine (PC) and phosphatidylinositol (PI). The focus of the analysis was to monitor the evolution of the individual PL species over maturation however, absolute content could be estimated by peak areas. A comparison between the five stages of seed maturity, demonstrated that there was a significant $(p<0.05)$ difference in their contents of various glycerophospholipid classes (Table 2). Interestingly, each stage was characterized by the abundance of one or two PL classes. For instance, immature (14 DAF) and mature (38 DAF) achenes were characterized by the highest abundance of $\mathrm{PG}$ that reached $70 \%$ of total phospholipids (TPL) while the achenes collected 5 DAF were PA rich (52\% of TPL) and those from fully mature seeds have recorded an equitable distribution of all classes. Moreover, at 26 DAF, PI (43\%) was the dominant class. It seems that the state of the achenes (unripe, ripe or fully ripe) highly modulate their need to one PL class or another and therefore the activation of the required complex of enzymes responsible for phospholipid synthesis and catalysis that respond to the maturity level. Considering these lipids are major components of cell membranes, the abundance of PA in immature seeds (5 DAF) and consequently the lysophosphatidic acyltransferase (LPAAT) that catalyses the synthesis of PA from lysophosphatidic acid reflect the need of seeds of this PL class to the synthesis of biomembranes in particular those of the storage lipid bodies (oleosome) and explain the high proportion of
TAGs (70\% of oil) in immature achenes (5DAF). Qualitatively, our results are partially in agreement with the literature. ${ }^{4,18,19}$ However, it is worth noting that the presence of low proportion of PC in all collection dates could be due the inactivation of PE-N-methyltransferase that catalyses the production of PC from PE via the CDP-DAG pathway or mostly to the conversion of $s n-1,2-$ diacylglycerol to TAG ( kennedy pathway) by the action of PA - phosphatase since the concentration of TAGs was more than $70 \%$ of oil during seed maturation whereas PC did not exceed $2 \%$ of total phospholipid classes. Baud and Lepinec ${ }^{8}$ reported that the synthesis of phospholipids in oilseeds is closely associated with TAG assembly. The former authors also showed the presence of several routes whereby acyl residues from $\mathrm{PC}$ can be incorporated into TAGs. Consequently, according to the former PL composition of the oil in particular the PG that reached $70 \%$ of total PL, we suggested $O$. acanthium seeds a suitable and valuable source for obtaining corresponding glycerophospholipid concentrates since previous works ${ }^{21}$ have shown a neuroprotective effect of PGs. They demonstrated that VP025, a preparation of phospholipid nanoparticles incorporating phosphatidylglycerol prevents the deficits in motor coordination in a proteasome inhibitor rat model of Parkinson disease.

\section{Phospholipid individual species during seeds development}

For structural elucidations, the molecular ions of PA, PI, PG, PE and PC were selected for MS/MS fragmentation experiments to generate characteristic product ion spectra as shown in Table 3. For PG, the main acyl chains were found to be palmitic (C16:0) linoleic (C18:2) and 
unexpectedly, linolenic (C18:3) acids. A typical product ion spectrum of the molecular ion of $\mathrm{m} / \mathrm{z}$ 743 (PG-PLn) is depicted in Fig. 3. We demonstrated for the first time that the yield of PG-C16:0/C18:3 varied from $\sim 10$ to $\sim 25$ of total PLs with stages 2 (14DAF) and 4 (38DAF) as the suitable periods of their accumulation. Considering the molecular species of $\mathrm{PG}$ in $O$. acanthium achenes, it appears that the first enzyme of the Kennedy pathway, GPAT has low specificity for oleoyl-coA and stearoyl-CoA and a preference for linoleate, linolenate or palmitate. Our hypothesis is in accordance to the biochemical studies of the FA distribution in the glycerolipid molecules of sunflower achenes. ${ }^{20}$ The dominating acyl chains combination of PA, PE and PI were respectively C16:0/C18:2, C16:0/C18:1, and C18:0/C18:1 but still be dependent on the stage of seed development. For instance, in the case of PI, 26 DAF were characterized by a higher content of stearoyl-oleoyl (PI-SO) and palmitoyl-linolenoyl PI (PI-PLn) whereas PI-PL and PI-PO were relatively more abundant in fully mature seeds (45 DAF). This unsaturated/saturated FA-rich composition indicated that enzymes involved in PI synthesis are more specific for glycerolipids carrying these acyl moieties. It has been indicated that PI synthase from corn and sunflower seeds shows a high selectivity for the synthesis of saturated-unsaturated PI species. ${ }^{22}$ These results prove that PLs provide more linolenic acid than TAGs that supply only $2 \%$ of total TAG species which contribute to their added value since the omega 3 fatty acids are known to possess important health-protecting effect. This was further supported by the determination of the contribution of the major fatty acids in PLs and TAGs assembly. Fig. 4 shows coordination between the TAG and the PL assembly. This is clear that the diminution of one or another fatty acid is compensated by the synthesis of the complementary form as a PL or TAG. However, this was not the case for stearate and oleate at 26 DAF where we observed same evolution for oleic and steraic acids assembled into PL and TAG. This could be due to the high activity of the stearoyl ACP- $\Delta 9$ desaturase and the enzymatic complex that assure the transportation and the activation of the former acyl groups (Acyl-ACP thioesterase and Coenzyme A) from the chloroplast to the endoplasmic reticulum in which they will adhere to the G3P. Moreover, it is noteworthy that during seed maturation we recorded a high influence of the maturity stage on the assembly and accumulation of structure lipids into the wild artichoke achenes. This observation reflects a genetic regulation of the enzymatic and the activators complexes involved in the FA synthesis and PL which is also dependent on the temperature, light and oxygen availability. We also suggest the influence of the variation of activators and repressors of the maturation program on the FAs metabolic pathways. The former studies ${ }^{23}$ in maize and A.thaliana reported the presence of a wide set of activators and repressors that control the gene expression programs essential to accomplish seed maturation. They also reported that the physiological and development investigation of seed oils is of particular interest.

\section{CONCLUSION}

In conclusion, storage and structure lipids were monitored during maturation of wild artichoke achenes with ESI-QTOF-MS during maturation. Sixteen molecular species of TAGs and five PL classes with 8 possible FA combinations were identified. We demonstrated that TAG synthesis was mostly coordinated with PL assembly which is highly influenced by the stage of seeds development. Additionally, our results showed that PL have a preference to incorporate linolenic acid better than TAGs so they provide more omega 3 fatty acid than TAGs. These findings have an important role in the prevention of many diseases and can be used in many cosmetic and pharmaceutical products. They also constitute a fingerprint of the oil. Moreover, by studying the evolution of these biochemical parameters during seeds development, we provide information about a new source of oil and a possible improvement of the oil content or quality with genetic engineering since the oil content is a quantitative trait based on numerous contributing genetic factors (overexpression/downregulation of target genes).

Acknowledgements: The authors gratefully acknowledge Dr. Justin Renaud for his reading and corrections. A large part of this work was carried out in the laboratory of mass spectrometry in the university of Ottawa, Ontario, Canada. And funded by the Tunisian ministry of higher education and scientific research. 
Table 3

Distribution of the molecular species of glycerophospholipids found in the wild artichoke achenes during maturation

\begin{tabular}{|c|c|c|c|c|c|}
\hline Classes de PLs & 5JAF & 14JAF & 26JAF & 38JAF & 45JAF \\
\hline \multicolumn{6}{|l|}{ ESM de PA ( \% des PL totaux) } \\
\hline$\overline{\mathrm{PA}-\mathrm{C} 16: 0 / \mathrm{C} 18: 3(\mathrm{~m} / \mathrm{z} \text { 669) }}$ & $0.92 \pm 0.05$ & $0.62 \pm 0.055$ & $0.42 \pm 0.045$ & $1.41 \pm 0.047$ & $0.3 \pm 0.18$ \\
\hline PA -C16:0/ C18:2 ( m/z 671) & $1.93 \pm 0.063$ & $0.66 \pm 0.08$ & $0.58 \pm 0.03$ & $0.7 \pm 0.16$ & $0.6 \pm 0.2$ \\
\hline PA -C16:0/ C18:1( m/z 673) & $8.36 \pm 0.17$ & $2.97 \pm 0.015$ & $1.69 \pm 0.24$ & $1.3 \pm 0.415$ & $2.87 \pm 1.725$ \\
\hline PA -C18:3/ C18:2 ( m/z 693) & $2.68 \pm 0.34$ & $0.56 \pm 0.015$ & $1.33 \pm 0.04$ & $0.795 \pm 0.3$ & $0.67 \pm 0.02$ \\
\hline PA -C18:2/ C18:2 ( m/z 695) & $22.63 \pm 0.1$ & $8.89 \pm 0.1$ & $4.98 \pm 0.01$ & $3.84 \pm 0.16$ & $6.85 \pm 3.74$ \\
\hline PA-C18:1/ C18:2 ( m/z 697) & $10.53 \pm 0.5$ & $3.8 \pm 0.2$ & $2.51 \pm 0.5$ & $1.83 \pm 0.38$ & $3.3 \pm 1.21$ \\
\hline PA-C18:1/ C18:1 ( m/z 699) & $3.93 \pm 0.1$ & $2.5 \pm 0.06$ & $1.89 \pm 0.45$ & $1.7 \pm 0.04$ & $4.38 \pm 0.27$ \\
\hline PA -C18:0/ C18:1( m/z 701) & $1.4 \pm 0.075$ & $1.11 \pm 0.016$ & $1.05 \pm 0.11$ & $0.9 \pm 0.1$ & $7.2 \pm 0.1$ \\
\hline \multicolumn{6}{|l|}{ ESM de PE ( $\%$ des PL totaux) } \\
\hline$\overline{\mathrm{PE}-\mathrm{C} 16: 0 / \mathrm{C} 18: 2(\mathrm{~m} / \mathrm{z} 714)}$ & $1.59 \pm 0.014$ & $2.51 \pm 0.036$ & $0.67 \pm 0.074$ & $0.96 \pm 0.02$ & $7.29 \pm 0.3$ \\
\hline PE-C16:0/ C18:1( m/z 716) & $0.9 \pm 0.036$ & $1.51 \pm 0.031$ & $0.67 \pm 0.03$ & $0.92 \pm 0.025$ & $3.23 \pm 0.16$ \\
\hline PE -C18:2/ C18:2 ( m/z 738) & $1.54 \pm 0.025$ & $2.34 \pm 0.075$ & $0.69 \pm 0.27$ & $2.85 \pm 1.11$ & $5.28 \pm 0.16$ \\
\hline PE -C18:2/ C18:1( m/z 740) & $0.87 \pm 0.015$ & $1.33 \pm 0.25$ & $0.59 \pm 032$ & $1.47 \pm 0.46$ & $2.94 \pm 0.16$ \\
\hline PE -C18:1/ C18:1( m/z742) & $2.3 \pm 0.02$ & $3.86 \pm 0.3$ & $2.77 \pm 0.13$ & $3.64 \pm 0.28$ & $2.69 \pm 0.43$ \\
\hline \multicolumn{6}{|l|}{ ESM de PG ( $\%$ des PL totaux) } \\
\hline$\overline{\mathrm{PG}-\mathrm{C} 16: 0 / \mathrm{C} 18: 3 \text { ( m/z 743) }}$ & $12.63 \pm 1.37$ & $21.45 \pm 0.06$ & $11.97 \pm 1.46$ & $24.69 \pm 1.18$ & $9.65 \pm 2.93$ \\
\hline PG -C16:0/ C18:2 ( m/z 745) & $21.16 \pm 0.91$ & $37.07 \pm 0.01$ & $20.97 \pm 0.1$ & $41.27 \pm 4.02$ & $17.05 \pm 1.14$ \\
\hline PG -C18:1/ C18:1( m/z 773) & $0.61 \pm 0.007$ & $0.7 \pm 0.012$ & $1.375 \pm 0.02$ & $1.23 \pm 0.26$ & $1.36 \pm 0.24$ \\
\hline PG -C16:0/ C18:1( m/z747) & $0.95 \pm 0.03$ & $2.29 \pm 0.02$ & $1.42 \pm 0.36$ & $2.81 \pm 0.23$ & $1.55 \pm 0.12$ \\
\hline \multicolumn{6}{|l|}{ ESM de PC ( $\%$ des PL totaux $)$} \\
\hline$\overline{\mathrm{PC}-\mathrm{C} 18: 3 / \mathrm{C} 18: 2(\mathrm{~m} / \mathrm{z} 767)}$ & $0.46 \pm 0.008$ & $0.77 \pm 0.035$ & $1.1 \pm 0.14$ & $0.76 \pm 0.1$ & $0.61 \pm 0.16$ \\
\hline PC-C18:2/ C18:2 ( m/z 769) & $0.57 \pm 0.02$ & $0.426 \pm 0.03$ & $0.46 \pm 0.02$ & $0.82 \pm 0.04$ & $0.65 \pm 0.14$ \\
\hline PC-C18:2/ C18:1( m/z 768) & $0.5 \pm 0.005$ & $0.57 \pm 0.025$ & $0.35 \pm 0.01$ & $0.43 \pm 0.01$ & $1.48 \pm 0.94$ \\
\hline \multicolumn{6}{|l|}{ ESM de PI ( $\%$ des PL totaux) } \\
\hline$\overline{\text { PI-C16:0/ C18:3 ( m/z 831) }}$ & $0.25 \pm 0.005$ & $0.326 \pm 0.06$ & $2.94 \pm 0.86$ & $3.21 \pm 0.025$ & $0.27 \pm 0.11$ \\
\hline PI -C16:0/ C18:2 ( m/z 833) & $1.48 \pm 0.28$ & $2.19 \pm 0.4$ & $1.58 \pm 0.43$ & $0.92 \pm 0.78$ & $16.8 \pm 1.35$ \\
\hline PI -C16:0/ C18:1 ( m/z 835) & $0.62 \pm 0.015$ & $0.61 \pm 0.006$ & $0.036 \pm 0.02$ & $0.38 \pm 0.21$ & $6.3 \pm 0.78$ \\
\hline PI-C18:2/ C18:1 ( m/z 859) & $0.39 \pm 0.013$ & $0.38 \pm 0.01$ & $0.4 \pm 0.03$ & $0.42 \pm 0.05$ & $0.69 \pm 0.1$ \\
\hline PI-C18:1/ C18:1 ( m/z 861) & $0.64 \pm 0.26$ & $0.32 \pm 0.021$ & $0.33 \pm 0.28$ & $0.42 \pm 0.12$ & $0.61 \pm 0.26$ \\
\hline PI-C18:1/ C18:0 ( m/z 863) & $0.24 \pm 0.002$ & $0.41 \pm 0.06$ & $37.36 \pm 1.35$ & $0.34 \pm 0.04$ & $1.47 \pm 0.51$ \\
\hline
\end{tabular}

Each value is a mean \pm standard deviation (SD) of a triplicate analysis performed on different samples. PA: Phosphatidic acid, PE: phosphatidylethanolamine, PG phosphatidylglycerol, PC: phosphatidylcholine,

PI: phosphatidylinositol. 


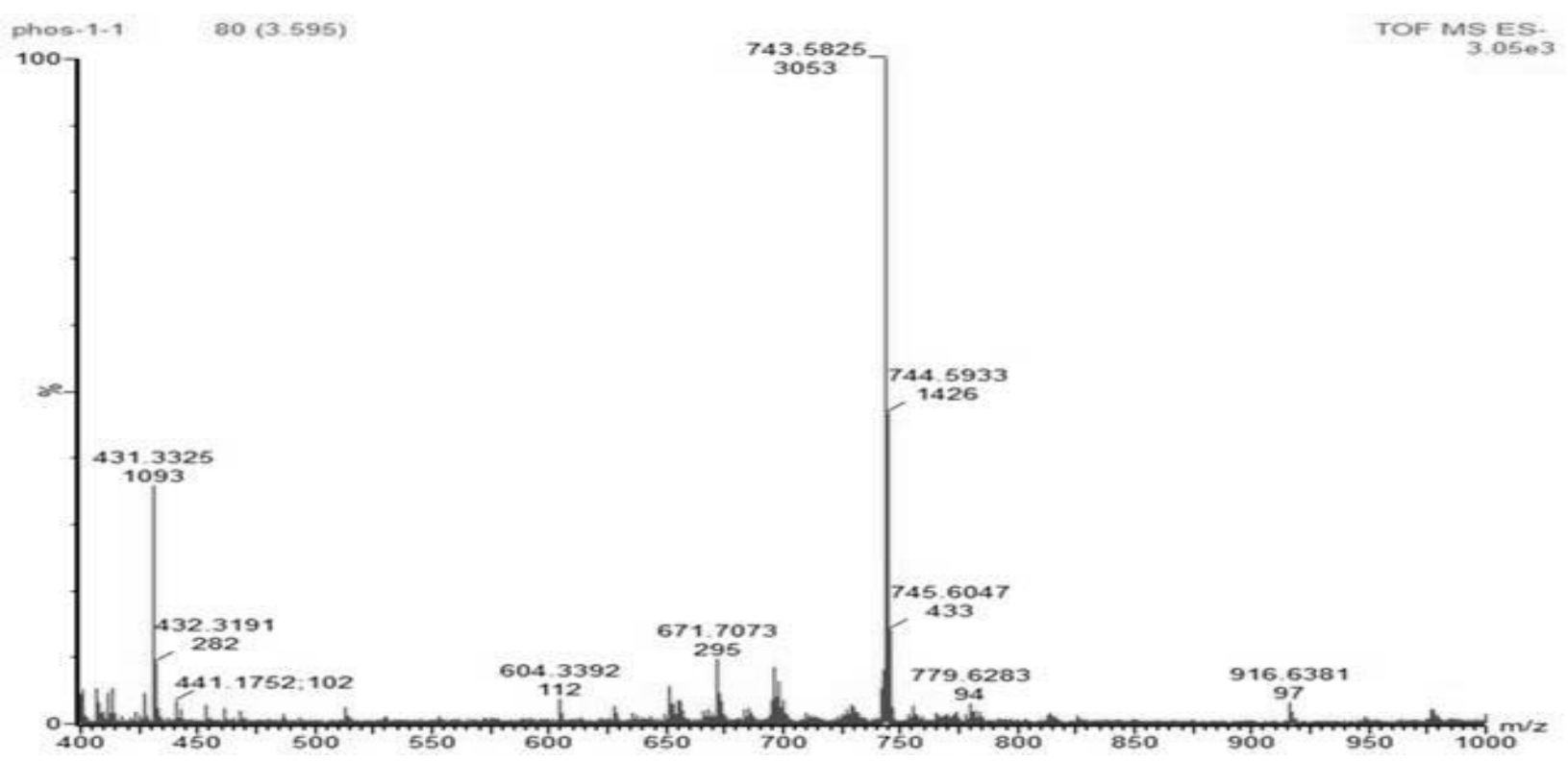

Fig. 3 - Mass spectrum profile of the molecular ion Phosphatidylglycerol (PG- PLn) determined with ESI-MS in the negative mode after fragmentation between m/z 400 and m/z 1000.

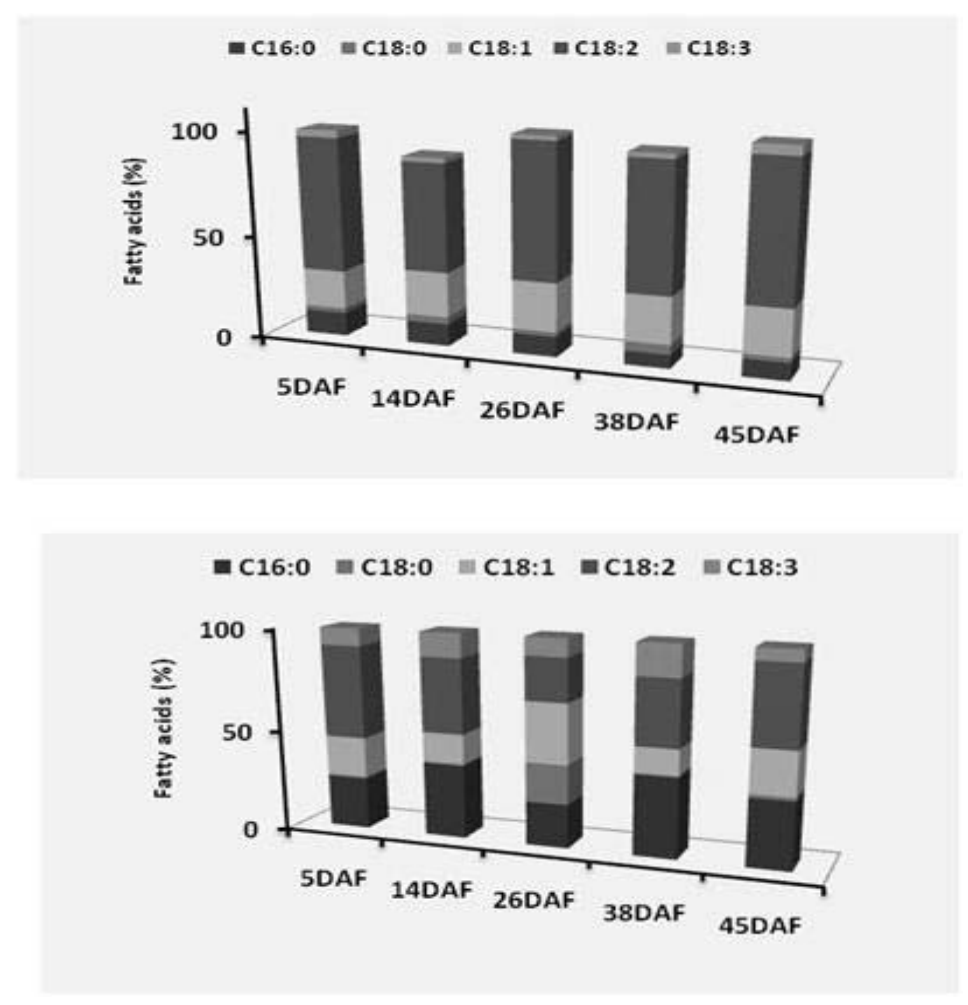

Fig. 4 - Fatty acid distribution into triacylglycerol (A) and phospholipid (B) species.

\section{REFERENCES}

1. P. B. Cavers, M. M. Qaderi, P. F. Threadgill and M. G. Steel, Can. J. Plant Sci., 2011, 9, 1-20.

2. M. M. Qaderi and P. B. Cavers, Ecosience, 2000, 7, 57-65.

3. B. Matthaus, M. M. Ozcan and F. Al-Juhaimi, Chem. Nat. Comp., 2014, 50, 1992-1993.

4. I. Zhelev, P. Merdzhanov, M. Angelova-Romova, M. Zlatanov, G. Antova, I. Dimitrova-Dyulgerova and A. Stoyanova, Bulg. J. Agric. Sci., 2014, 20, 622-627.
5. O. M. Arfaoui, J. Renaud, H. Ghazghazi, S. Boukhchina and P. M. Mayer, Nat. Prod. Res., 2014, doi.org/10.1080/ 14786419.2014.940944.

6. Z. Wiesman and B. P. Chapagain, Methods. Mol. Biol. 2009, 579, 315-36.

7. S. Harrabi, S. Boukhchina, H. Kallel and P. M. Mayer, J. Cereal Sci., 2010, 51,1-6.

8. S. Baud and L. Lepinec, Prog. Lipid. Res., 2010, 49, 235-249.

9. K. L. Duffin, J. D. Henion and J. J. Shieh, Anal. Chem., 1991, 63, 1781-1788. 
10. A. O. Cherif, N. Leveque, M. B. Messaouda, H. Kallel and F. Moussa, Food Chem., 2013, 138, 1095-1100.

11. N. Tlili, T. H. Trabelsi, J. Renaud, A. Khaldi P. M. Mayer and S. Triki, J. Am. Oil. Chem. Soc., 2011, 88, 1787-1793.

12. S. Harrabi, S. Boukhchina, H. Kallel and M. P. Mayer, Can. J. Anal. Sci. Spec., 2008, 53, $22-27$.

13. J. Craig, P. Barratt, H. Tatge, A. Déjardin, L. Handley, C. D. Gardner, L. Barber, T. Wang, C. Hedley, C. Martin and A. M. Smith, The plant J., 1999, 17, 353-362.

14. H. Fong-Fu and J. Turk, J. Am. Soc. Mass Spectrom., 2010, 21, 657-669.

15. J. B. Renaud, S. Overton and P. M. Mayer, Inter. J. Mass Spect., 2013, 352, 77-86.

16. M. Miquel and J. Browse, "Lipid biosynthesis in developing seeds", in J. Kigel, J. Galili (Eds.), "Seed development and germination" New York : Marcel Dekker, 1995, p. 169-93.
17. J. J. Salas, J. Saanchez, U. S. Raml, A. M. Manaf, M. Williams and J. L. Harwood, Prog. Lipid. Res., 2000, 39, 151-180.

18. N. T. Ul'chenko, E. I. Gigienova, K. L. Seitanidi and A. U. Umarov, Chem. Nat. Comp., 1978, 14, 595-601.

19. N. T. Ul'chenko, E. I. Gigienova, U. A. Abdullaev and A. U. Umarov, Chem. Nat. Comp., 1979, 5, 612-615.

20. J. J. Salas, F. E. Martínez and R. Garcés, Lipids, 2006, 41, 805-811.

21. P. Fitzgerald, A. Mandel, A. E. Bolton, A. M. Sulluvan and Y. Nolan, Behav. Brain. Res., 2008, 195, 271-274.

22. U. S. Ramli, J. J. Salas and P. A. Quant, New Phytol., 2009, 184, 330-339.

23. M. Santos-Mendoza, B. Dubreucq, S. Baud, F. Parcy, M. Caboche and L. Lepiniec, The Plant J.l, 2008, 54, 608620. 